\title{
Haploidentical bone marrow stem cell transplantation for hematological diseases: experience of single public Mexican hospital
}

\author{
Uendy Pérez-Lozano, José Ruiz-Ovalle, Diego Cruz-Contreras
}

Hematology Department of High Speciality Medical Unit “Manuel Ávila Camacho”, Mexican Institute of Social Security, Puebla, Mexico

Contact: Dr. Diego Cruz

E-mail: dr_diego_cruz@hotmail.com

\section{Introduction}

Unavailability of complete HLA-matched related donors and lack of a bone marrow Registry in Mexico is one of our main problems when performing allogeneic stem cell transplantations (alloSCT) in the patients who require hematopoietic grafting. The aim of our work was to study haploidentical stem cell transplantation (haploSCT) as an alternative way for the patients lacking available stem cell donors.

\section{Materials and methods}

The study group included 20 patients (16 ALL, 1 SMD, 1 AML, 1 CML). Their median age was 30 (3-58) years old. Nine patients (45\%) received reduced-intensity conditioning (RIC) regimens, and 11 (55\%) received myeloablative conditioning (MAC) regimen. Bone marrow was used as a stem cell source. All the patients received high-dose cyclophosphamide (HDCY) on day +3 and +4 , Tacrolimus and MMF as acute graft-versus-host-disease (aGVHD) prophylaxis.

\section{Results}

Overall survival (OS) in both cohorts was 58\% (OS rate was $60 \%$ for MAC cohort, with a median follow-up of 23.8 months, and 57\% for RIC group, follow-up of 14 months). Two patients (18\%) relapsed in each cohort. Two patients died from infectious complications in MAC cohort, whereas none of the patients was lost for these reasons in RIC co- hort. Two (18\%) patients from each group had grade IV aGVHD, but neither patient died from aGVHD. Median values for neutrophilic and platelet engraftment in RIC cohort was 15.3/27.8 days, respectively. Appropriate values for MAC cohort were 19.4/30.7 days. All the patients from RIC cohort reached $100 \%$ chimerism as compared with $55 \%$ in MAC group.

\section{Conclusions}

HaploSCT is a feasible transplant mode which may be performed in Mexico for all patients with agressive malignant hematological diseases who have no an available donor.

\section{References}

1. Kanakry CG, Fuchs EJ, Luznik L. Modern approaches to HLA-haploidentical blood or marrow transplantation. Nat Rev Clin Oncol. 2016; 13(1):10-24

2. Luznik L, et al. HLA-haploidentical bone marrow transplantation for hematologic malignancies using nonmyeloablative conditioning and high-dose, posttransplantation cyclophosphamide. Biol Blood Marrow Transplant. 2008; 14(6): 641-650.

\section{Keywords}

Haploidentical bone marrow stem cell transplantation, highdose cyclophosphamide. 


\title{
Гаплоидентичная трансплантация стволовых клеток костного мозга при гематологических заболеваниях: одноцентровый опыт мексиканской больницы
}

\author{
Уэнди Перес-Лозано, Жозе Руис-Овалье, Диего Крус-Контрерас \\ Отдел гематологии Специализированное медицинское отделение «Мануэль Авила Камачо», Мексиканский институт \\ социального страхования, Пуэбла, Мексика
}

\section{Введение}

Ограниченная доступность НLA-совместимых родственных доноров и отсутствие регистра доноров костного мозга в Мексике является одним из главных препятствий к проведению аллогенных трансплантаций гемопоэтических клеток (алло-ТГСК) у пациентов, требующих пересадки гемопоэтических клеток. Цель нашей работы состояла в изучении гаплоидентичной ТГСК (гапло-ТГСК) в качестве альтернативного варианта для пациентов с отсутствием подходящих одноров стволовых клеток.

\section{Материалы и методы}

Мы наблюдали 20 пациентов, включая случаи ОЛЛ (16), МДС (1), ОМЛ (1), ХМЛ (1). Их средний возраст составлял 30 (3-58) лет. Девять больных (45\%) получали кондиционирование сниженной интенсивности (РИК), а 11 (55\%) - миелоаблативное кондиционирование (МАК). В качестве источника стволовых клеток применяли костный мозг. Всем больным применяли высокодозную терапию циклофосфамидом (ЦФ) в день +3 и +4 , а также Такролимус и ММФ для профилактики острой реакции «трансплантат против хозяина» (оРТПХ). Результаты. Общая выживаемость (OB) в обеих группах была 58\% (60\% для группы с применением МАК при среднем сроке наблюдения 23,8 мес. против 57\% в группе РИК при сроке наблюдения 14 мес.). По 2 пациента $(18 \%)$ в каждой группе имели рецидивы основного заболевания. Двое больных погибли из-за инфекционных осложнений в группе МАК, тогда как в группе РИК ни один из пациентов не был потерян по этим причинам. По 2 пациента (18\%) из каждой группы имели признаки
oPTПX IV степени, но ни один из них не погиб в связи с РТПХ. Медианы сроков приживления по нейтрофилам и тромбоцитам в группе РИК составила, соответственно, 15.3/27.8 дней. Аналогичные показатели для группы с МАК-кондиционированием были: 19.4/30.7 дней. У всех пациентов из группы с РИК-терапией отмечен выход на 100\%-ный донорский химеризм, по сравнению с $55 \%$ случаев в группе с миелоаблативной терапией.

\section{Выводы}

Гапло-ТГСК является выполнимым видом трансплантации, который может проводиться в Мексике всем пациентам с агрессивными злокачественными гематологическими заболеваниями, которые не имеют доступного донора.

\section{Литература}

1. Kanakry CG, Fuchs EJ, Luznik L. Modern approaches to HLA-haploidentical blood or marrow transplantation. Nat Rev Clin Oncol. 2016; 13(1):10-24

2. Luznik L, et al. HLA-haploidentical bone marrow transplantation for hematologic malignancies using nonmyeloablative conditioning and high-dose, posttransplantation cyclophosphamide. Biol Blood Marrow Transplant. 2008; 14(6):641-650.

\section{Ключевые слова}

Гаплоидентичная трансплантация гемопоэтических стволовых клеток, циклофосфамид в высоких дозах. 